\title{
Completely anatomical autogenous whole mitral valve
}

\author{
J. C. VAN DER SPUY \\ From the Division of Thoracic Surgery, Pretoria General Hospital and the University of Pretoria, \\ Republic of South Africa
}

A study of the mitral valve (Van der Spuy, 1958, $1960,1963,1964 a, 1964 b)$ has shown that the valve does not merely function as would a mechanical unit with but an opening and a closing mechanism. It is a complicated unit with numerous anatomically distinct features upon all of which the continued successful function of the valve during a period of many years depends (Psalm 90, verse 10 ).

The detailed anatomical and functional features which were taken into consideration in the manufacture of an entirely anatomical whole mitral valve from autogenous tissues will be published elsewhere (van der Spuy, 1964b).

To construct such an anatomical valve a portion of pericardium is sandwiched between two stainless steel anterior cusp plates (Fig. 1) and the

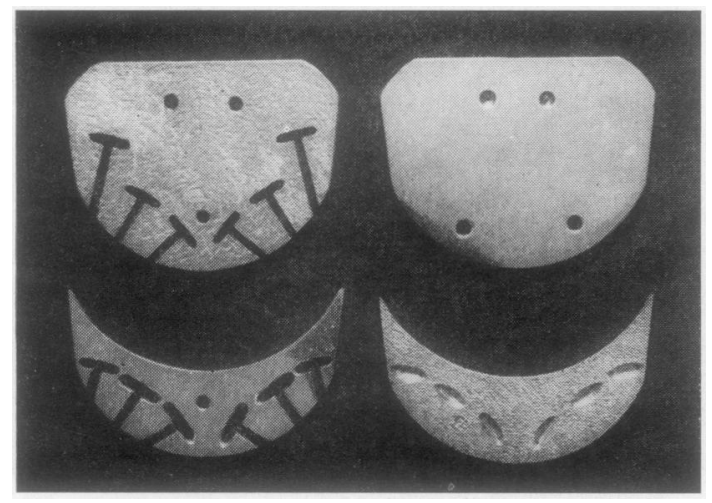

FIG. 1. Two large anterior and two small posterior stainless steel cusp plates. The two outer cusp plates are provided with T-shaped slits. The two inner cusp plates are scooped out opposite the transverse members of the slits. A chorda tendinea is sutured to the margin of a cusp opposite the base of the vertical, and to the ventricular surface of the cusp through the transverse member of a T-shaped slit. The inner surfaces of the cusp plates are rough to prevent slipping of the pericardial cusps. cusp is excised along with a $\frac{1}{8}$-in. $(3 \cdot 175-\mathrm{mm}$.) wide fringe of pericardium. A posterior cusp is similarly excised with the aid of two posterior cusp plates.

The size and shape of the cusp plates and the position of the T-shaped slits for the chordae tendineae are shown in Figure 2.

A mitral valve G-clamp (Fig. 3) holds the four cusp plates and chordae tendineae in position while the latter are being sutured to the margins and outer (ventricular) surfaces of the cusps. Each set of chordae tendineae is prepared by dividing the one extremity of a $\frac{1}{2}$ in. $\times 3$ in. $(12 \cdot 7 \times$ $76.2 \mathrm{~mm}$.) strip of ilio-tibial band, removed with the aid of a fasciotome, into six equal divisions and by ligating the free end of each division to prevent fraying. The opposite end of the iliotibial strip is firmly tied with No. 2 silk, and the ends are left long. The chordae are formed by stripping each of the six divisions down to the main ligature. A second silk ligature is tied $\frac{1}{2}$ in. to 1 in. $(12 \cdot 7-25 \cdot 4 \mathrm{~mm}$.), depending on the size of the left ventricle (the papillary muscles of a small left ventricle associated with pure mitral stenosis are shorter and thinner than those of the bigger left ventricle of mitral incompetence), from the first.

Each chorda tendinea is then sutured in turn first to the margin and then to the outer (ventricular) surface of the opposite halves of each cusp, as indicated by the T-shaped slits, with figure-8 3-0 silk sutures in such a way that the central chorda in each group of three will be $\frac{5}{8}$ in. $(15.875 \mathrm{~mm}$.) long, as determined by the distance of a G-clamp needle, which is passed through the eye of the ligature at the base of the chordae, from the base of a central T-shaped slit in an outer cusp plate. Each chorda is ligated to the margin and to the ventricular surface of the cusp, and the ends of the sutures are left long. The free end of the chorda is folded back upon itself in a direction towards the main chordal stem. By 

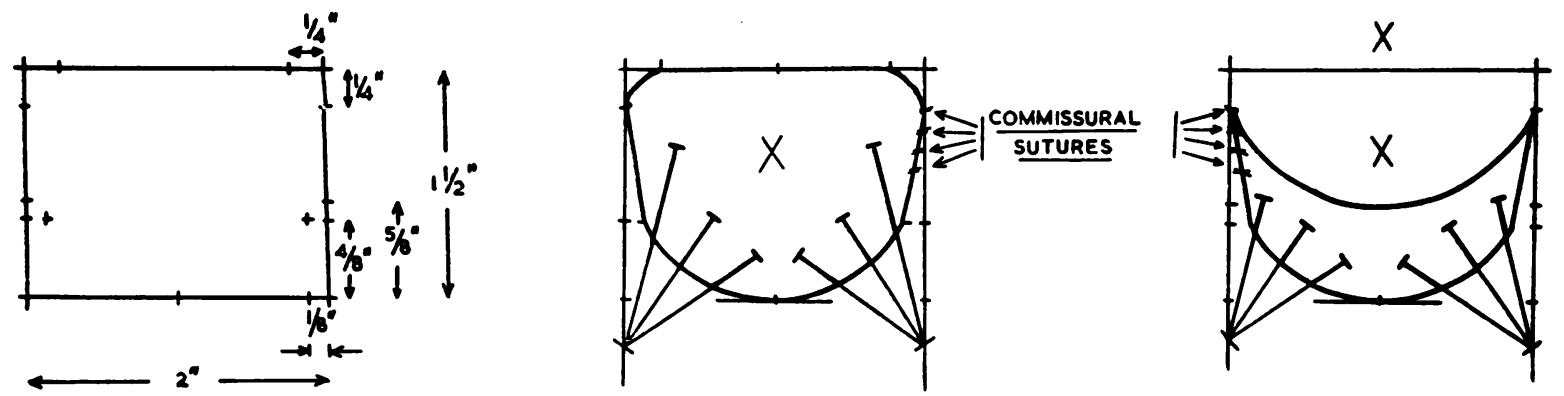

FIG. 2. Shows the size and shape of the anterior and posterior cusp plates.

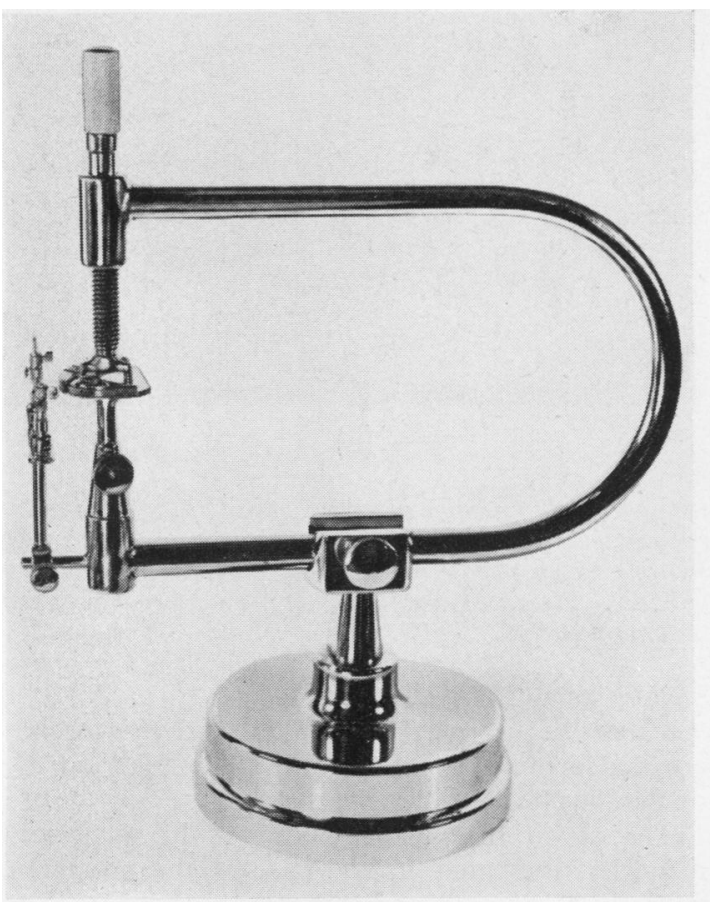

(a)

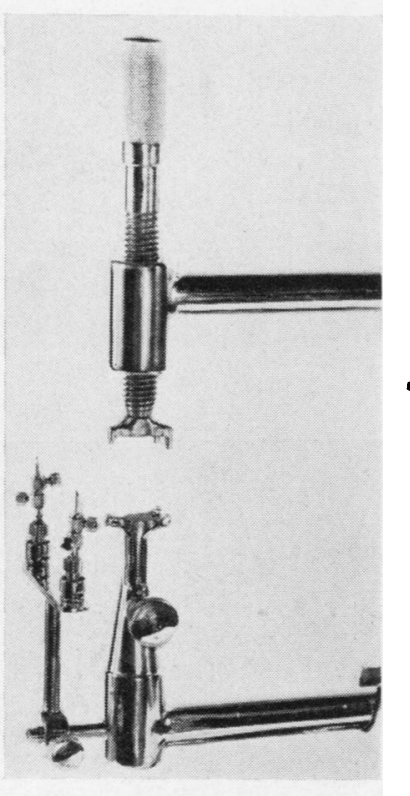

(b)

FIG. 3. Mitral valve G-clamp: (a) side view; (b) close-up view. The four cusp plates hold the two cusps between them while the chordae tendineae are sutured to the margins and outer surfaces of the cusps. The distance of the G-clamp needles from the margins of the cusp plates determines the length of the chordae tendineae.

using these same ligatures the reflected chorda is once more ligated on the ventricular surface and at the margin of the cusp. The excess chorda is amputated. The G-clamp is turned upside down and the chordae tendineae are similarly sutured to the margin and outer surface of the opposite cusp. Four 3-0 silk sutures (Fig. 2) are passed through the free margins of the cusps at each commissure and tied. A semi-circular length of No. 0 nylon thread is sutured to the upper free margin of the anterior and of the posterior cusp to stabilize the valve. The cusp plates are removed and the whole valve is ready for use (Fig. 4).

Each common chordal stem is imbedded in a papillary muscle of the same side by passing a long, flat, malleable, $\frac{3}{16}$ in. $(4.762 \mathrm{~mm}$.) wide 'needle' through the base and apex of a papillary muscle from outside the heart. The ends of the silk ligature around the free end of the common chordal stem are passed through the eye of the 


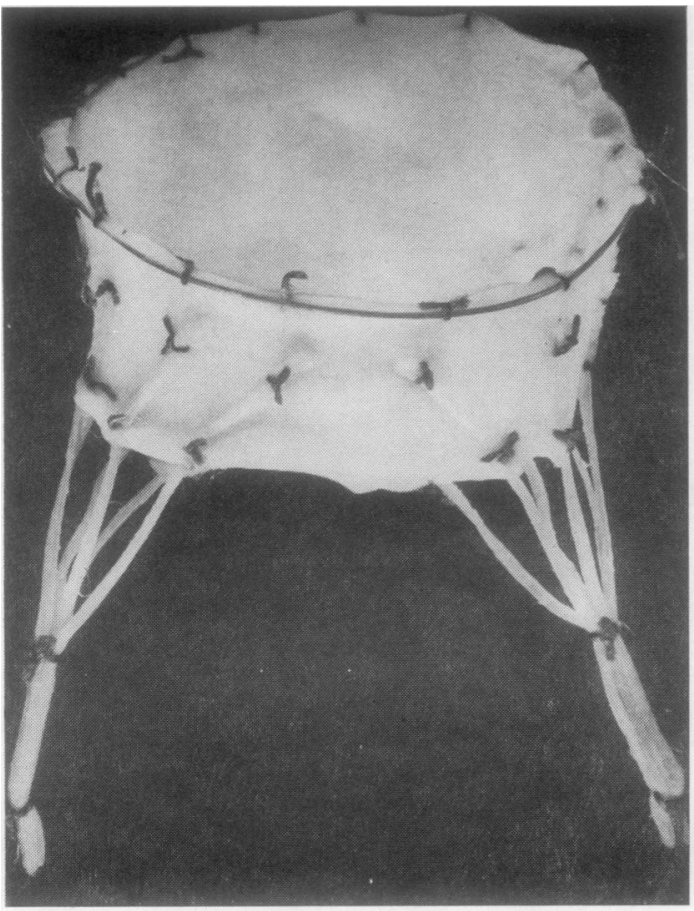

(a)

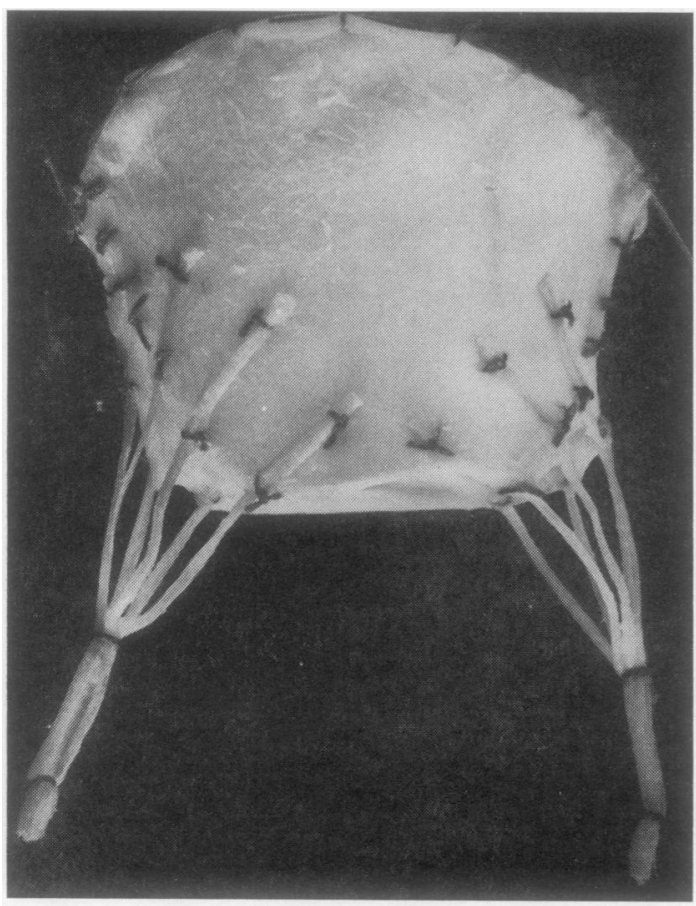

(c)

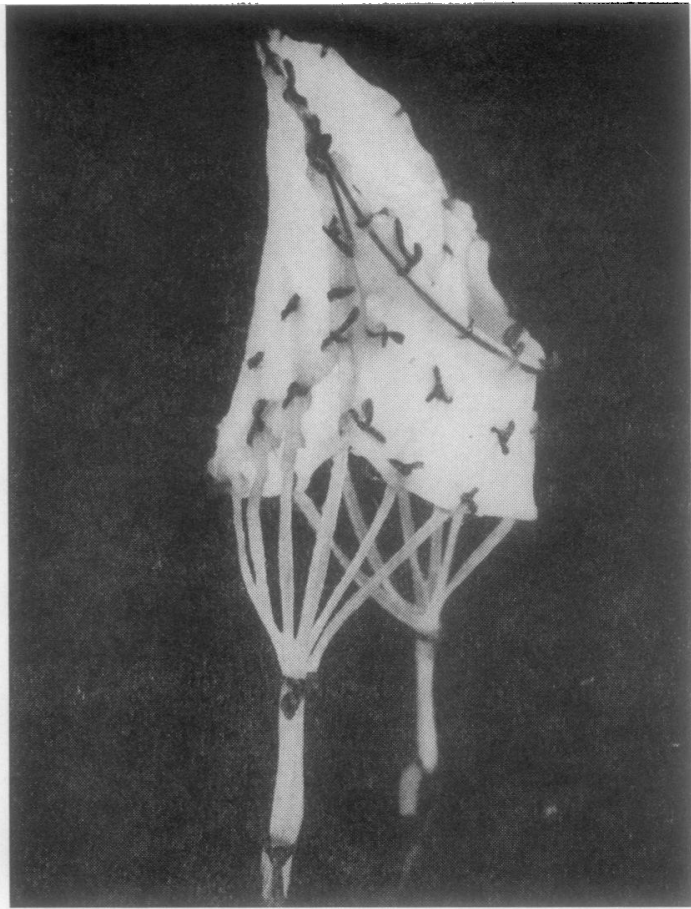

(b)

rIG. 4. Fully anatomical whole mitral valve from autogenous pericardium and ilio-tibial band: (a) posterior view $ᄋ$ showing the short posterior and long anterior cusps and the obliquely placed mitral ring; (b) anterior view; and (c) lateral view.

'needle', the latter is withdrawn, and the threads $\underset{x}{\times}$ are tied around a small roll of teflon felt on the outside surface of the heart.

The nylon threads are removed in short seg- 8 ments, as indicated, as the base of the prosthetic valve is being sutured to the ring of the excised 9 valve with running 3-0 silk sutures. The anterior $D$ cusp sutures are passed $\frac{1}{4}$ in. $(6 \cdot 35 \mathrm{~mm}$.), and the posterior cusp sutures $\frac{1}{8}$ in. $(3.175 \mathrm{~mm}$.), deep to $\mathrm{N}$ the nylon thread, thereby leaving the anterior cusp $1 \frac{1}{4}$ in. $(31.75 \mathrm{~mm}$.) and the posterior cusp $\stackrel{N}{N}$ $\frac{1}{2}$ in. $(12 \cdot 7 \mathrm{~mm}$.) long.

The valve, as described above, has been used for the correction of mitral stenosis with incom- 0 petence in two patients. At the time of writing (six $\stackrel{\odot}{\varnothing}$ weeks post-operatively) the first patient has no $\stackrel{?}{?}$ murmurs (only a disappearing pericardial rub) 꾸 and the mitral closing sound is slightly accentuated. The second patient died 10 hours post- $\stackrel{\cap}{\varrho}$ operatively. Digital palpation of the valve after $\stackrel{\otimes}{\propto}$ termination of the cardio-pulmonary bypass and 
auscultation during the post-operative period indicated competent closure and complete opening of the prosthetic valve.

The author wishes to thank Mr. B. J. Badenhorst, senior heart-lung machine technician, who made the G-clamp and the cusp plates, Mr. D. Annandale, learner cardiac and heart-lung machine technician, who made the valve illustrated in Fig. 4, and Mrs. I. R. Wenk for the photographs.

\section{REFERENCES}

Van der Spuy, J. C. 1958). The functional and clinical anatomy of the mitral valve. Brit. Heart J., 20, 471.

(1960). Mitral stenosis with posterior cusp incompetence. Read at the Second Bi-annual Meeting of the Southern African Cardiac Society at Cape Town, October, 1960.

- (1963). The clinical pathology of rheumatic mitral endocarditis. Brit. Heart J., 25, 763 .

- $-(1964 a)$. The surgical approach to the mitral valve and the technique of correcting insufficiency of the anterior and of the posterior cusp with pericardium. S.Afr. med. J., in the press.

(1946b). Considerations in the prosthetic construction of a completely anatomical whole mitral valve from autogenons tissues. Ibid., in the press. 